TITLE:

\title{
Bioelectrocatalytic endpoint assays based on steady-state diffusion current at microelectrode array
}

\section{$\operatorname{AUTHOR}(\mathrm{S}):$}

Noda, Tatsuo; Hamamoto, Katsumi; Tsutsumi, Maiko; Tsujimura, Seiya; Shirai, Osamu; Kano, Kenji

\section{CITATION:}

Noda, Tatsuo ...[et al]. Bioelectrocatalytic endpoint assays based on steady-state diffusion current at microelectrode array. Electrochemistry Communications 2010, 12(6): 839-842

\section{ISSUE DATE:}

2010-06

URL:

http://hdl.handle.net/2433/128892

\section{RIGHT:}

(C) 2010 Elsevier B.V.; This is not the published version. Please cite only the published version.; この論文は出版社版でありません。引用の際に は出版社版をご確認ご利用ください。 
1 Bioelectrocatalytic endpoint assays based on steady-state diffusion current at

2 microelectrode array

3

4 Tatsuo Noda, Katsumi Hamamoto, Maiko Tsutsumi, Seiya Tsujimura, Osamu Shirai, and Kenji

5 Kano*

6

7 Division of Applied Life Sciences, Graduate School of Agriculture, Kyoto University, Sakyo,

$8 \quad$ Kyoto 606-8502, Japan

9

10 "Corresponding author: Tel: +81-75-753-6392; fax: +81-75-753-6456; E-mail:

11 kkano@kais.kyoto-u.ac.jp

12

13 Abstract

14 Highly reproducible bioelectrocatalytic endpoint assays are described. The method is based on a

15 complete redox conversion of a substrate to a redox mediator with a corresponding redox

16 enzyme and an amperometric detection of the reduced mediator on a diffusionally independent

17 microelectrode array. The current reaches a steady state within a few seconds and is proportional

18 to the number of the integrated microelectrodes. The method has successfully been applied to

19 histamine detection at micro-molar level and glucose detection at milli-molar level.

21 Keywords: Bioelectrocatalysis, Endpoint assay, Microelectrode array, Histamine assay, Glucose 22 assay 


\section{Introduction}

25

Electrochemical analysis with biological functions such as biosensors have been received much attention in the field of clinical analysis, food industry and environmental monitoring, hence numerous efforts have been devoted to develop rapid, reliable and accurate electrochemical biosensors [1]. However, most of the conventional amperometric biosensors have an intrinsic disadvantage in the issue that the response current is liable to be affected by either enzyme kinetic-related factor or diffusion-related factor of substrate (and mediator in mediated bioelectrocatalysis) [2]. This issue is frequently addressed by using permeable membrane-coated electrodes with raised enzyme activity under convectional conditions [3]. However, it is difficult to strictly control the permeability of membranes on miniaturized biosensors and to realize high reproducibility. Coulometry as an absolute quantitative analysis is an alternative of bio-sensing $[4,5]$, but is often time-consuming.

Spherical diffusion plays an important role at microelectrode and provides steady-state current even under quiescent conditions [6]. In our best knowledge, however, there is no report on micro-biosensors utilizing such spherical diffusion. One of the reasons is that the current is usually within or below nano-ampere range, which might not be convenient for practical use. Microelectrode array (MEA) is designed by integration of several microelectrodes to increase the current intensity in various amperometric sensors [7-11]. In MEAs, the distance between microdisc electrodes should be larger than 12 times of the radius $(r)$ in order to ensure diffusional independence of the microelectrodes [12], although the geometry and the shape of microelectrodes are important factors determining the timescale [9-11]. It is not easy to fabricate such ideal MEAs, and diffusion-layer overlapping seems to occur at most of MEAs. The other reason is that sufficiently high enzyme activity is required to satisfy the diffusion-controlled condition of substrate in bioelectrocatalytic reactions. 
Herein, we describe a reproducible amperometric detection method by monitoring steady-state diffusion current in mediated bioelectrocatalysis. First, we will propose a fabrication method of an diffusionally independent MEA. In addition, the endpoint method was incorporated in order to eliminate the effect of enzyme activity change and to increase the applicability of the method in practical bioassays, where the electron equivalent of substrate is completely transferred to that of mediator with the aid of redox enzyme in solution. The concentration of the reduced mediator (for the oxidation of substrate) is determined from the steady-state current at the MEA. The amperometric endpoint assays were applied to determining histamine at micro-molar level with histamine dehydrogenase $(\mathrm{HmDH})$ and ferricyanide (as a mediator) and glucose at milli-molar level with pyrroloquinoline quinone (PQQ)-dependent glucose dehydrogenase (PQQ-GDH) and benzoquinone (as a mediator). The performance will

60 be discussed in detail.

61

\section{Experimental}

63

\subsection{Reagents and materials}

Recombinant $\mathrm{HmDH}$ was expressed in Escherichia coli and purified as described previously [13]. The protein concentration was determined using a modified Lowry method with a DC Protein Assay Kit (Bio-Rad, USA) with bovine serum albumin as a standard protein. PQQ-GDH (EC 1.1.5.2 $4200 \mathrm{U} \mathrm{mg}^{-1}$ ) was obtained from Amano Enzyme (Japan). Mutarotase of analytical reagent grade and were used without further purification. D-Glucose stock solution was prepared with a phosphate buffer $(0.1 \mathrm{M}, \mathrm{pH} 7)$ and stored overnight to reach the mutarotative equilibrium. Epoxy resin (Alardite 2020) and silver-epoxy resin (Dotite D-753) were obtained from Huntsman (USA) and Fujikura Kasei (Japan), respectively. 
The fabrication scheme and the structure of our MEA are illustrated in Fig. 1. Firstly, a Pt wire $(20 \mu \mathrm{m}$ in diameter; Niraco, Japan) was inserted into a silicon tube (i.d. $0.5 \mathrm{~mm})$. The tube was filled half with the epoxy resin (overnight, $55^{\circ} \mathrm{C}$ ). The silver-epoxy resin was crammed into the tube from the opposite side $\left(4 \mathrm{~h}, 55^{\circ} \mathrm{C}\right)$. The resin was ejected from the silicon tube and is called Pt-embedded rod. A blank rod was also prepared in the same manner without using Pt wire. The Pt-embedded rods and the blank rods were inserted together in a silicon tube (i.d. 3 mm) (Fig. 1a). The Pt-embedded rods were arrayed to keep away from the neighboring ones in a distance between the Pt wires of at least $500 \mu \mathrm{m}$ (Fig. 1b). The number of the Pt-embedded rod in the MEA $(N)$ was varied from 1 to 7 . In this paper, a single microelectrode is described as MEA with $N=1$, for simplification in description. After arraying the rods, the space among the rods was filled with the epoxy resin. The rod array was then ejected from the silicon tube and mounted in a glass tube (i.d. $3 \mathrm{~mm}$ ). The silver-epoxy resin was crammed into the glass tube from the opposite side and a lead wire was inserted in the silver-epoxy resin for the electrical connect with the Pt-embedded rods. The glass tube was filled with the epoxy resin in the back side (Fig. 1c). The surface of the MEA was polished to a flat and mirror finish with sandpaper (\#1500) and alumina slurry $(0.05 \mu \mathrm{m})$.

92

\subsection{Electrochemical measurements and endpoint assays of histamine and glucose with MEA}

Cyclic voltammetry and amperometry were carried out in a three-electrode system on an

ALS CHI 611B electrochemical analyzer (BAS Inc.) equipped with a faraday gage in a laboratory-made electrolysis cell at a total volume of $1.0 \mathrm{~mL}$. The MEA, a Pt wire and an $\mathrm{Ag}|\mathrm{AgCl}| \mathrm{KCl}$ (sat.) were used as the working, counter and reference electrodes, respectively. All potentials in this paper are referred to the reference electrode. The total volume of the analytical 
solution was $1.0 \mathrm{~mL}$.

$100 \quad$ In histamine detection, $10 \mu \mathrm{L}$ of a histamine sample solution was added to $1.0 \mathrm{~mL}$ of 0.1

$101 \mathrm{M}$ phosphate buffer ( $\mathrm{pH} 7.0)$ containing $500 \mathrm{nM} \mathrm{HmDH}$ and $5 \mathrm{mM} \mathrm{K}_{3}\left[\mathrm{Fe}(\mathrm{CN})_{6}\right]$. After

102 incubation at room temperature for $20 \mathrm{~min}$, the amperometric detection was performed at $+0.6 \mathrm{~V}$.

103 In glucose detection, $100 \mu \mathrm{L}$ of a glucose sample solution was added to $1.0 \mathrm{~mL}$ of $30 \mathrm{mM}$

104 MOPS buffer ( $\mathrm{pH}$ 7.0) containing $21 \mathrm{U}$ PQQ-GDH, $9 \mathrm{U}$ mutarotase, $25 \mathrm{mM}$ benzoquinone and

$1053 \mathrm{mM} \mathrm{CaCl}_{2}$. After incubation at room temperature for $15 \mathrm{~min}$ under anaerobic conditions with

$106 \mathrm{Ar}$, the amperometric detection was performed at $+0.85 \mathrm{~V}$ under quiescent conditions.

107

108

\section{Results and discussion}

109

\subsection{Characterization of the MEA}

All of the MEAs $(N=1,3,7)$ showed typical sigmoidal steady-state shape for $\left[\mathrm{Fe}(\mathrm{CN})_{6}\right]^{3-}$

112 at $20 \mathrm{mV} \mathrm{s}^{-1}$ and the current was proportional to $N$ (Fig. 2). Such sigmoidal response was observed at scan rates of $5-100 \mathrm{mV} \mathrm{s}^{-1}$ and was independent of the scan rate. These results support that the steady-state spherical diffusion layer of each microelectrode is not overlapped with that of the adjacent ones. The steady-state limiting current $\left(i_{\text {lim }}\right)$ is given by:

$$
i_{\lim }=4 N n F r D c
$$

117 where $n, D$, and $c$ are the number of electron, diffusion coefficient, and the bulk concentration

118 of analyte, respectively. $F$ is the Faraday constant. Thus, once $\mathrm{Nr} D$ is determined experimentally

119 with a given MEA, $c$ can be easily evaluated from $i_{\text {lim. }}$. In potential-step chronoamperometry, the 120 current reached into almost steady state within 2 s, as shown in the inset of Fig. 2. In the 121 following, the current after $5 \mathrm{~s}$ was taken as $i_{\mathrm{lim}}$. 
124 Histamine analysis is one of the major concerns in clinical and food chemistry because

125 histamine is a transmitter in the nervous system and a powerful biological marker of food

126 freshness $[14,15]$. $\mathrm{HmDH}$ catalyzes a 2-electon oxidation of histamine to give imidazole

127 acetaldehyde [16]. Several redox compounds such as $\left[\mathrm{Fe}(\mathrm{CN})_{6}\right]^{3-}$ and osmium (III) complexes

128 work as electron acceptors of the reduced $\mathrm{HmDH}[17,18]$. In addition, the product imidazole

129 acetaldehyde is proposed to be oxidized non-enzymatically to imidazole acetate by some

130 electron acceptor in solution [17]. When $\left[\mathrm{Fe}(\mathrm{CN})_{6}\right]^{3-}$ was used as an electron acceptor, the

131 overall reaction is expected as follows.

132 histamine $+4\left[\mathrm{Fe}(\mathrm{CN})_{6}\right]^{3-}+2 \mathrm{H}_{2} \mathrm{O} \rightarrow$ imidazole acetate $+4\left[\mathrm{Fe}(\mathrm{CN})_{6}\right]^{4-}+\mathrm{NH}_{3}+4 \mathrm{H}^{+}$

133 The succeeding non-enzymatic 2-electron oxidation will increase sensitivity twice in the histamine determination.

The $i_{\lim }$ of $\left[\mathrm{Fe}(\mathrm{CN})_{6}\right]^{4-}$ in the endpoint assay detection with the MEA $(N=7)$ was in a very nice linear correlation to $c$ (histamine) with a correlation coefficient larger than 0.999 over a wide range of $c$ (histamine) from 10 to $1000 \mu \mathrm{M}$. The detection limit was $8.0 \mu \mathrm{M}$ at an $S / N$ ratio of 3, which is higher than some reported works [17-20]. In addition, the detection limit can be improved by increasing the number of embedded microelectrodes [7]. The relative standard

140 deviation was $4.1 \%$ for five separate measurements at $10 \mu \mathrm{M}$ histamine, in which the MEA

141 surface was polished with alumina slurry before each measurement. The sensitivity ( $4 \mathrm{NnFrD})$ was $6.6 \times 10^{-2} \mathrm{~A} \mathrm{M}^{-1}$ for $N=7$ and was proportional to $N\left(2.9 \times 10^{-2} \mathrm{~A} \mathrm{M}^{-1}\right.$ for $N=3$ and $9.2 \times$

$14310^{-3} \mathrm{~A} \mathrm{M}^{-1}$ for $N=1$ ). From the result, the averaged $4 n F r D$ value is evaluated as $9.5 \times 10^{-3} \mathrm{~A}$

$144 \mathrm{M}^{-1}$ for the histamine analysis with the MEA. In a separate experiment, the $4 F r D$ value of $145\left[\mathrm{Fe}(\mathrm{CN})_{6}\right]^{4-}$ was evaluated as $2.4 \times 10^{-3} \mathrm{~A} \mathrm{M}^{-1}$ at the MEA in $0.1 \mathrm{M}$ phosphate buffer $(\mathrm{pH} 7.0)$.

146 The comparison of the two values can verify our expectation that $n=4$ (Eq. 2). 
149 Metabolic disorders like diabetes mellitus are reflected by human blood glucose 150 concentrations higher or lower than the normal range of 4.4-6.6 mM [21]. When we apply our 151 amperometric endpoint assay to such high concentrations of the analyte, very fast enzymatic conversion is required. PQQ-GDH catalyzes the 2-electron oxidation of $\beta$-D-glucose with several artificial electron acceptors. The activity is very high [22]. From the kinetic viewpoint, we selected $p$-benzoquinone as an electron acceptor in the PQQ-GDH reaction [23]. The overall reaction is written by:

We first tried to amperometric trace of the enzyme kinetics by measuring time dependence of $i_{\text {lim }}$ of hydroquinone generated in the reaction of Eq. (3). The PQQ-GDH reaction appeared to reach an endpoint within 15 min under the present conditions, but $i_{\lim }$ was gradually increasing after $15 \mathrm{~min}$. This is due to the mutarotation. Therefore, it is essential to accelerate the mutarotation proceeding simultaneously with the PQQ-GDH reaction. For this purpose, mutarotase was added in the enzyme solution. Under such conditions, the $i_{\text {lim }}$ reached a constant value within $15 \mathrm{~min}$. Furthermore, the steady-state value of $i_{\lim }$ is accounted for $161 \%$ of that in the absence of mutarotase (at $15 \mathrm{~min}$ ). The value is very good agreement with the concentration ratio of the total glucose against $\beta$-D-glucose in mutarotative equilibrium. These results indicate that the complete redox conversion of the total glucose to hydroquinone is successfully achieved under the present conditions.

The $i_{\lim }$ for the glucose determination showed a linear relationship against $c$ (glucose) with correlation coefficients larger than 0.998 . The relative standard deviation for five independent measurements was $1.2 \%$ at $c($ glucose $)=5.0 \mathrm{mM}$ with the $\operatorname{MEA}(N=7)$. The sensitivity $(=4 N n F r D)$ was $4.0 \times 10^{-2} \mathrm{~A} \mathrm{M}^{-1}$ for $N=7,1.8 \times 10^{-2} \mathrm{~A} \mathrm{M}^{-1}$ for $N=3$, and $5.7 \times 10^{-3} \mathrm{~A} \mathrm{M}^{-1}$ for $N=1$. By considering that $n=2$ in this case, the average value of $4 F r D$

173 is evaluated as $2.8 \times 10^{-3} \mathrm{~A} \mathrm{M}^{-1}$. The value is in good agreement with that $\left(2.8 \times 10^{-3} \mathrm{~A} \mathrm{M}^{-1}\right)$ 
174 evaluated from separate experiments on $i_{\lim }$ of hydroquinone in the same buffer solution

175 containing the enzymes.

176

177

\section{Conclusion}

178

The diffusionally independent MEA electrode proposed here gives very stable and

179 reproducible $i_{\text {lim }}$. Once the conditional parameter $4 N n F r D$ is estimated, the bulk concentration

180 of analyte can be easily determined from $i_{\text {lim }}$ within a few seconds. The amperometric method

181 can be successfully combined with endpoint enzyme assays using mediated bioelectrocatalysis,

182 in which $i_{\text {lim }}$ of the mediator generated in the enzyme reaction was determined with the MEA.

183 The principle is applicable to almost all redox enzymatic assays, including micro-plate analysis.

184 Selection of better mediator will improve the proposed method into the practical use level.

185

\section{References}

187 1. B.J. Privett, H.S. Jae, M.H. Schoenfisch, Anal. Chem., 80 (2008) 4499-4517.

188 2. B. Limoges, J. Moiroux, J.-M. Savéant, J. Electroanal. Chem. 521 (2002) 1-7.

189 3. W.J. Albery, P.N. Bartlett, J. Electroanal. Chem. 194 (1985) 211-222.

190 4. M. Fukaya, H. Ebisuya, K. Furukawa, S. Akita, Y. Kawamura, S. Uchiyama, Anal. Chim. $191 \quad$ Acta $306(1995)$ 231-236.

192 5. S. Tsujimura, A. Nishina, Y. Kamitaka, K. Kano, Anal. Chem., 81 (2009) 9383-9387.

193 6. K. Aoki, Electroanalysis, 5 (1993) 627-639.

194 7. O. Ordeig, J. del Campo, F.X. Muñoz, C.E. Banks, R.G. Compton, Electroanalysis 19 195 (2007) 1973-1986.

196 8. X.-J. Huang, A.M. O'Mahony, R.G. Compton, Small 5 (2009) 776-788.

197 9. T.J. Davies, S. Ward-Jones, C.E. Banks, J. del Campo. R. Mas, F.X. Muñoz, R.G. Compton, $198 \quad$ J. Electroanal. Chem, 585 (2005) 51-62. 
199 10. T.J. Davies, R.G. Compton, J. Electroanal. Chem, 585 (2005) 63-82.

200 11. D. Menshykau, X.J. Huang, N.V. Rees, F.J. del Compo, F.X. Muñoz, R.G. Compton, Analyst, 134 (2009), 343-348.

202

12. Y. Saito, Rev. Polarogr. 15 (1968) 177-186.

203

13. N. Fujieda, N. Tsuse, A. Satoh, T. Ikeda, K. Kano, Biosci. Biotechnol. Biochem. 69 (2005) $2459-2462$.

205

14. M.A. Beaven, A. Robinson-White, N.B. Roderick, G.L. Kauffman, Klin. Wochenschr. 60 (1982) 873-881.

207

15. L. Lehane, J. Olley, Int. J. Food Microbiol. 58 (2000) 1-37.

16. M. Tsutsumi, N. Fujieda, S. Tsujimura, O. Shirai, K. Kano, Biosci. Biotechnol. Biochem. $72(2008)$ 786-796.

210 17. R. Yamada, N. Fujieda, M. Tsutsumi, S. Tsujimura, O. Shirai, K. Kano, Electrochemistry 76 (2008) 600-602.

212 18. K. Takagi, S. Shikata, Anal. Chim. Acta 505 (2004) 189-193.

213 19. M. Niculescu, I. Frébort, P. Peč, P. Galuszka, B. Mattiasson, E. Csöregi, Electroanalysis 12 (2000) 369-375.

215 20. M.G. Loughran, J.M. Hall, A.P.F. Turner, V.L. Davidson, Biosens. Bioelectron. 10 (1995) $216 \quad 569-576$

217 21. J. Wang, Chem. Rev. 108 (2008) 814-825.

218 22. L. Ye, M. Hämmerle, A.J.J. Olsthoorn, W. Schuhmann, H.-L. Schmidt, J.A. Duine, A. Heller, Anal. Chem., 65 (1993) 238-241.

23. N. Okumura, T. Abo, S. Tsujimura, K. Kano, Electrochemistry 74 (2006) 639-641.

Figure Captions

223 Fig. 1. (a) Schematic diagram of the integration process, (b) the photo image and (c) the 
224 structure of MEA.

225

226 Fig. 2. Cyclic voltammograms obtained at MEA with $N=$ (a) 1, (b) 3 and (c) 7 for $1 \mathrm{mM}$

$227\left[\mathrm{Fe}(\mathrm{CN})_{6}\right]^{3-}$ in $1 \mathrm{M} \mathrm{KCl}$, at a scan rate $20 \mathrm{mV} \mathrm{s}^{-1}$. Inset: chronoamperometric responses for

$228\left[\mathrm{Fe}(\mathrm{CN})_{6}\right]^{4-}$ in $1 \mathrm{M} \mathrm{KCl}$ in potential step from $-0.1 \mathrm{~V}$ to $+0.6 \mathrm{~V}$ at $\mathrm{MEA}(N=1,3,7$ from

229 bottom to top). 
(a)

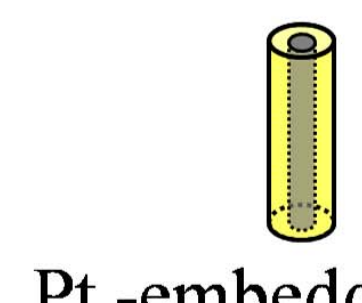

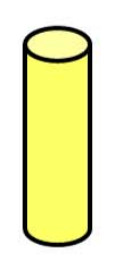

Blank rod (b)

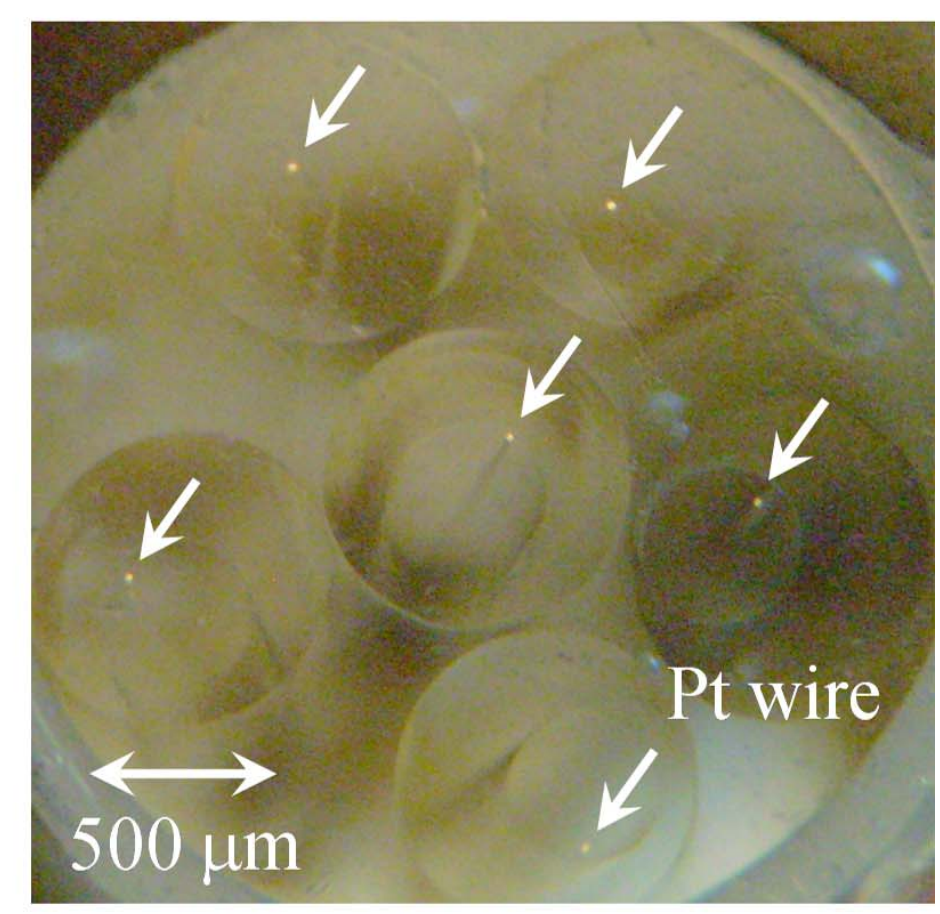

(c)

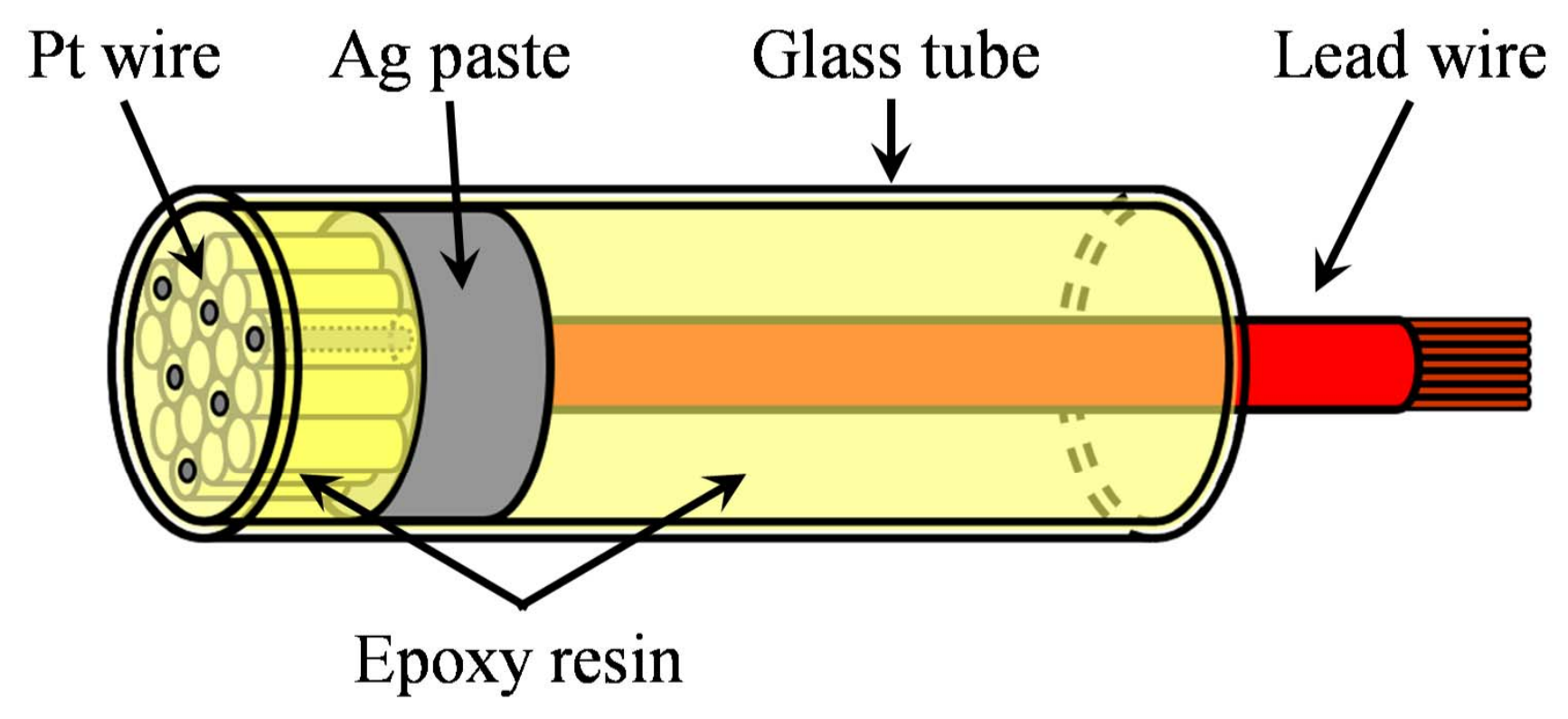




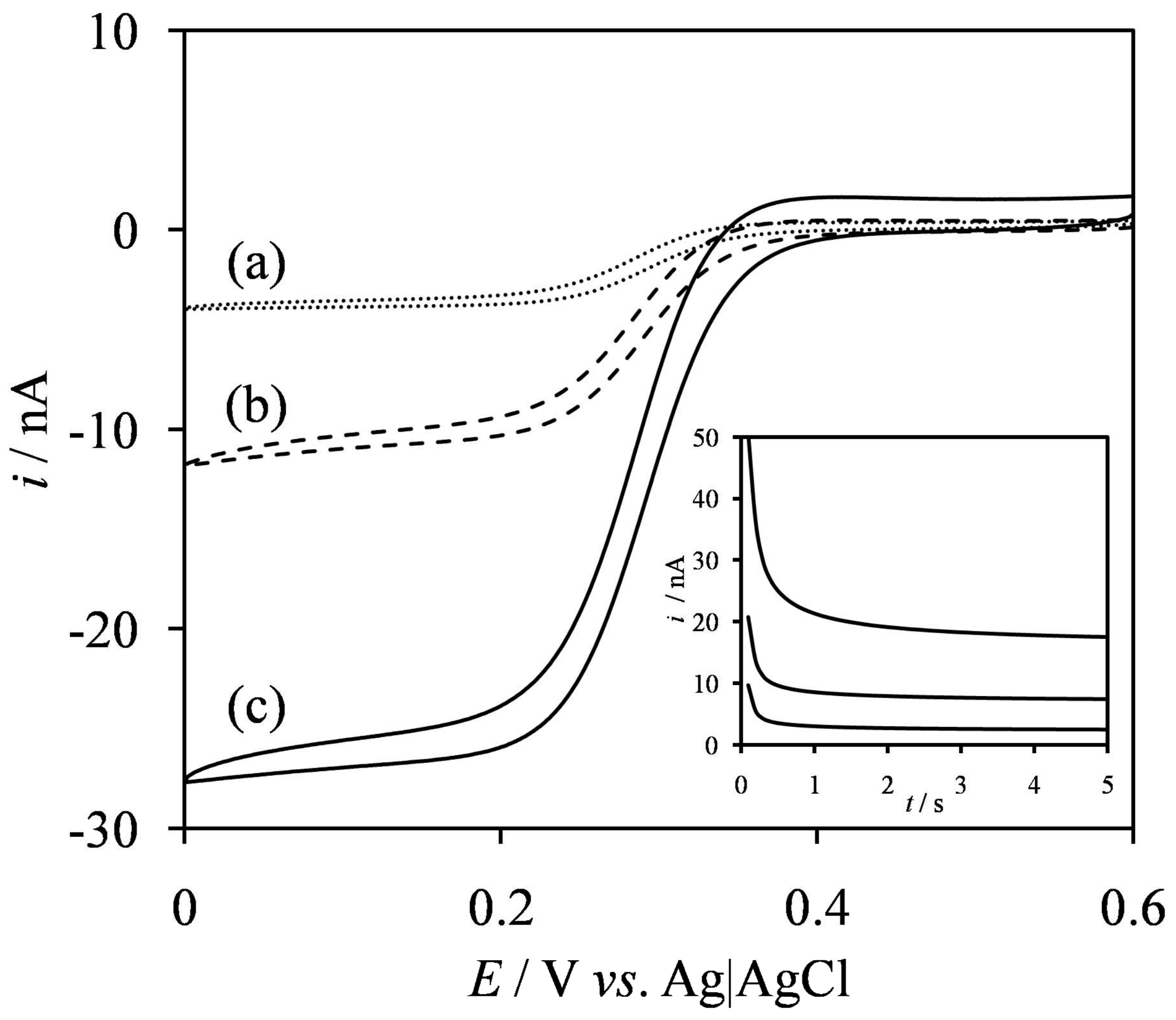

